\title{
Modeling and analyzing the Russian fuel and energy production and consumption in interaction with its national and regional economies
}

\author{
Vladimir Buzulutskov, Ekaterina Lyubimova, Vitalia Markova, Nikita Suslov*, and Viktor \\ Tchurashev \\ Institute of Economics and Industrial Engineering of Siberian Branch of the Russian Academy \\ of Sciences, Novosibirsk, Russia
}

\begin{abstract}
This paper discusses issues of a system energy modeling and the approaches to modeling and studies carried out in this field and by the Institute of Economics and Industrial Engineering, Siberian Branch of the Russian Academy of Science. The SONAR-Energy project, being developing by the Institute, includes several models of the national and regional energy systems of Russia, including those from macrolevels to models of large energy units. A central model (OMMM-Energy) belongs to the category of MRIO models, though it has its own features. A modern version includes 6 regions of Russia and 45 sectors of the national economy. It is applied to predict the development of the energy sector of Russia within its national economy and to assess efficiency of large energy projects implementation. A final part of the paper discusses what consequences the displacement of Russian coal and gas from European markets would bring to the economy of the country.
\end{abstract}

\section{Introduction}

This paper considers issues of development and use of applied models for analysis and forecasting of the Russian energy sector. We discuss a complex of models collectively known as Sector Oriented and National Models' Adjustment Research for Energy Sector (SONAR-Energy) that was developed in the Institute of Economics and Industrial Engineering, Siberian Branch of the Russian Academy of Sciences (IEIE SB RAS). This complex covers various elements of the energy sector with separate models complementing each other. The Optimization Multi-Industry Multi-Region Model (OMMM) along with OMMM-Energy (a natural block of the fuel and energy complex) is the core element of the SONAR-Energy system. In its turn, OMMM-Energy is an extension of the classical OMMM developed under guidance of a distinguished Soviet and Russian economist Alexander Granberg [1] who made significant contribution to the theory and practice of regional economy. The main advantage of OMMM-Energy is a combination of several approaches, such as interindustry input-output analysis, interregional input-output analysis, and the fuel and energy balance method. That is why this model is considered an effective

\footnotetext{
*Corresponding author: nsus@academ.org
} 
tool for assessing social and economic consequences of energy production, processing and consumption policies.

The SONAR-Energy complex has been complemented with other model structures and model complexes, which can be used separately as well. The above-mentioned studies are the result of the IEIE's multi-year research on the energy industry of Russia and its regions considered as part of the national economy or regional economic systems. The basic principles of the complex design and construction are:

- to present a consolidated description of internal and external relations observed in the energy complex in one model structure;

- to consider all interrelations of various type - intersectoral and interregional ones, and those between sectors due to their competition for major economic resources;

- to specify key lines of research; create basic model modules which are rather autonomous but able to function jointly to shape "the core of the system";

- to create model structures appropriate for "an arising problem"; such structures are also coordinated with the core of the system;

- to create means allowing an interactive mode of SONAR-Energy use and "a dialogue" between an expert (researcher) and this model complex; and

- to create means and models reflecting specific subsystems and energy units.

An important application of SONAR-ENERGY is macroeconomic assessment of energy projects and impacts of external shocks on the Russian economy. Historically, it was used for analyzing a range of interaction problems concerning the national economy and the energy sector. The most noticeable was estimation of:

- the consequences of the fact that energy-intensive industries were allocated mostly in the south of Siberia;

- economic efficiency of gasification of the southern zone of Siberia;

- economic consequences of a higher rate of development of the nuclear energy sector;

- economic efficiency of higher energy saving measures in regions and sectors of the Russian economy;

- consequences of distribution of compression heating pumps;

- efficiency of expansion of non-traditional renewable sources;

- consequences of displacement of Russian energy carriers from European markets.

The last two problems are discussed in the final part of this paper as examples of SONAR-ENERGY application.

\section{External links of the SONAR-ENERGY}

At present, the IEIE identifies three model complexes which are rather closely connected with each other but intended for modeling and analyzing various economic problems.

The first complex CAMIN (Complex Analysis of Multisectoral Information) based on the Dynamic Multisectoral Model (DMM), was developed by the famous Soviet economist N.F. Shatilov [2-3] in the middle of the 1960s and since then it has been enhanced by the IEIE. These tools are tailored for modeling and analyzing the dynamics and sectoral structure of the Russian economy [4-5].

The second complex called as SYRENA (Synthesis of Regional and National Systems) and based on OMMM models is widely applied to analyzing spacial proportions. Such models are developed for various time periods, spacial networks, and sectoral structures, and they focus on analysis of interregional and regional problems and are applied to predict the spacial development of the Russian economy [6-8].

The third complex, called as SONAR (Sector Oriented and National models' Adjustment Research) is based on various models aimed at modeling sector systems 
(mostly for modeling basic industrial multisectoral complexes) and it incorporates separate "sector branches". Its main ideas are:

- to make a soft unification of major macroeconomic models which are adjusted to the same national, regional, and sectoral forecasts; and

- to enhance macroeconomic models with model structures of the sectoral and regional levels.

These principles allowed researchers, firstly, to coordinate their economic studies and, secondly, to consider flexibly the specifics of economic spheres under study. This is very important since sectoral complexes, even basic ones, may be differently sensitive to impacts of natural and geographical conditions, technologies applied, factors and resources consumed, and therefore, the challengers to be addressed.

Having started the development of the SONAR project, it's a top part (or "a core") was suggested to be as follows: the OMMM developed by the IEIE makes up the uppermost level and the lower level - sectoral OMMMs which have several detailed blocks of corresponding multi-industry complexes, such as an energy industry, machine-building complex, forestry, and petrochemical complexes. Further, each sectoral OMMM could be added with other models relating to units of a specified multi-industry complex in order to specify its internal interrelations.

Such a type of models includes detailed sectoral models or regional units, investment project models, and models of regional development programs. The principles and methods of interaction between models could also differ. Sectoral OMMMs interacted through a top OMMM. Vertical links were realized by both exchange of the parameters, being the solutions of models of the other levels, and quantitative assessments. In practice, the links between models in all cases were not based on the strict algorithms called as "coordination of models" and could be characterized as "a soft coordination" of them.

In course of time, the SONAR project incorporated almost all the research results obtained by the IEIE in the field of the sectoral systems modeling, since it provided their integration and coordination within a framework of a united variant of the economic development strategies for Russia and Siberia. At the same time, it allowed the researchers to apply their own approaches and maintain the best IEIE traditions, such as a deep expert analysis and individual creativity in choosing and designing models and methodical devices.

All these projects (KAMIN, SYRENA, and SONAR) are constructed on a common statistical and methodological base and can supplement each other. However, their autonomous application has been observed too.

An energy branch of the SONAR, called as the SONAR-Energy, was developed within in a general stream of sectoral studies in the middle of the 1980s. It was based on the OMMMEnergy model. Later, we enhanced the SONAR-Energy with other model structures and model complexes, which can be used separately. The specified studies are a result of the research on modelling the Russian and regional complexes (considering regions as a part of the national or regional economies) obtained by the IEIE over many years.

\section{The SONAR-Energy architecture}

The modern architecture of SONAR-Energy reflects its interrelations with the general SONAR system constructed as unification of sectoral models for other sectoral complexes [9]. First of all, we are talking about coordination of common development parameters of the national economy, its major sectors, and regions through applying various detailed or specialized OMMMs. Interrelations with a related SYRENA complex are also possible and have been implemented in practice. For example, having created the development strategy for Novosibirsk Oblast, we found it convenient to incorporate both SYRENA and SONAR complexes in the strategy model [10]. 
Further, interactions of the central model in the OMMM-ENERGY project are detailed both in regional and sectoral aspects. Regional links are realized through the SIBAFC (System of Balanced Forecasting Calculation) which allows a complex forecast of the regional economy. In its turn, the latter is a system that includes several structures, such as basic models of regional balances, macroeconomic forecast models, microeconomic forecast models for each sector of the regional economy, input-output balance forecast models, and energy consumption models.

Nowadays, this system has been implemented for two programs for Novosibirsk Oblast. They are the Energy Efficiency and Energy Security Program and Social and Economic Development Strategy 2025. This system was mostly designed for long-term forecasts and it is working in coordination with the static model of the regional economy, which includes links between production and budgetary spheres of the economy of Novosibirsk Oblast. The calculations made by applying the SIBAFC complex are transferred to the block of regional energy models to find parameters of regional energy balances. The complex also allows building and analyzing forecasted aggregated energy balances of territories.

Sectoral links are realized by energy models applicable to large administrative regions such as Siberia or Russia. These models are applicable to modelling a national energy industry and its subsystems too, for example, the coal industry. The corresponding complexes were used to justify the prospects of Russia coal and power generating industries as well as the energy strategy for Siberia. The most important of them are described in the following chapter of this paper.

The major lines of research made within the SONAR-Energy project focus on several stable model constructions; other network models for the development of the oil and gas territories (also called megaproject models [11]) have been used beside OMMM-ENERGY and SIBAFC.

Analysis of economic agents' behavior is based on theoretical models describing how various prices and institutional conditions impact decisions made by producers and consumers of energy resources. The practical economic balance models or econometric ones are applied to testing such models and calculating parameters of the economic agents' behavior. Their application in the general SONAR-Energy system can be realized due the fact that input parameters for applied behavior models, for example, sectoral prices and output, are calculated by models of the higher level. Moreover, the parameters estimated within behavior models, such as demand elasticity coefficients for energy resources calculated for each type of energy carriers, sectors, and regions, can be used in the OMMM- Energy and SIBAFC, as well as in calculating energy resources demands for energy models.

An important line of research is an estimation of efficiency of large projects for production, transportation, and consumption of energy resources with suggesting both application and no application of new technologies. In this case, OMMM-ENERGY allows assessing macroeconomic impacts of proposed measures, for example, on production structure shifts, changes in macroeconomic indicators, and distribution and size of investment in regional or sectoral aspects. The efficiency estimates obtained (in the form of a GDP and consumption fund growth (drop) observed in the last year of the forecast) includes both direct and indirect effects and can differ from investors' ones. Such estimates can be calculated using energy models and other investment project models which calculate net present values and internal revenue rates. Thus, the application of SONAR-Energy allows complex assessments of application efficiency of new technologies and investment projects.

\section{Analyzing and modeling intersectoral and interregional interactions}




\subsection{International approaches}

International research on creating intersectoral and interregional input-output models started in the 1950s in the USA. The most fundamental interregional input-output model (IRIO Model) was presented in [12]. It was based on the Interregional Input-Output Tables and assumed available statistical data on mutual product supplies between all sectors and regions under study. The model required building so-called matrices of local (regional) and interregional technical coefficients representing both employed technologies and the structure of interregional supplies of all types of production in detail. The requirement of availability of statistical data obviously predetermined a limited application of such an approach in practice. Nevertheless, it has remained a major theoretical instrument and the basis for other approaches.

A response to this challenge was the emergence of another major approach called the Multiregional Input-Output (MRIO) approach and developed practically simultaneously in Europe [13] and the USA [14]. It is based on intraregional tables (Intraregional InputOutput Tables) the availability of which are higher as compared to interregional ones (Interregional Input-Output Tables) in statistical systems of the countries-developers. Moreover, this approach requires information on the total regional import and use of sectoral productions in all regions without distinguishing recipient sectors. On assumption that shares of products exported from other regions are identical, interregional trade coefficient matrices are built for each sector of a given region. Then they serve as a basis for estimation of matrices of regional and interregional technical coefficients.

The MRIO approach described above has remained most popular up to now. However, other approaches have been offered too. For example, applying a gravity approach, which assumes specification of variables as a function of regional output, W. Leontieff and A. Straut offered gravity MRIO model [15] where variables of inter-provincial trade were defined. W. Leontieff developed another model, i.e. Balanced Regional Model [16] where national and regional markets were represented as different blocks, while the end demand of the common block of regional markets - divided by regions. Subsequent studies appeared in the 1970-90s (a few models were developed in the USA, Europe, Japan, China of Australia). At present, the MRIO approach is applied to analyzing regional growth and interregional interactions [17-20]. Another important application of MRIO models is research on consequences and efficiencies of regional projects [21-22].

\subsection{Russian approach: an optimization multiregional multisectoral model}

The optimization multiregional multisectoral model was proposed in the 1960s and received a systematic description in A.G. Granberg's works [1]. The first forecast for the economy of the Soviet Union for 1966-1975 (6 sectors and 11 economic regions of the country) was made in 1967. Another series of forecasts for 1975-1990 was made by 1978 . Later, in 1978-1982, by invitation from the United Nations General Assembly, the Siberian interregional intersectoral models developed under the leadership of A.G. Granberg were applied to the development of the UN project on the Future of the World Economy [23].

The basis of the OMMMs is intraregional IO matrices for all regions. To model interregional interactions, parameters of import and export to and from adjacent regions, instead of trade coefficients, are imbedded into product balance equations. Thus, the model includes not only production IO matrices, but also interregional transportation ones. Moreover, an international export and import are given only for cross-border ones.

The inclusion of transportation matrices in the model makes optimization of transportation flows possible and desirable. This, in its turn, makes the production and transportation structure more flexible, which is important if we make long-term forecasts by 
applying the model. A comparative analysis of regional production efficiencies becomes applicable too as well as an incorporation of additional alternative technologies for the same production (for example, a comparison of various technologies for producing the same product). On the other hand, as the model remains linear, constraints on certain output variables are required to be imbedded.

As the model requires production dynamics, it includes an investment block. All parameters of output, final and intermediate demand, and demand for production factors are determined for the last year of the period for each of the regions under study. In addition, total investments for each type of fixed capital are calculated. This can be made by setting the law of investment growth for each type of fixed capital. Normally, we use a power law and add functional dependences between investments made in the last year of the period and their total amount over the period. Such dependencies are included in the model as linear approximations. Modeling an investment process requires to identify two types of IO variables, namely production at capacity available in the beginning and production at capacity introduced over the forecast period, the capital intensity coefficients for which are calculated differently.

As an objective function for optimization, we use total consumption of households (normally, with fixed total consumption patterns in regions and sectors), including consumption of public goods.

\subsection{OMMM-Energy is a central model in the SONAR- Energy}

The central model of an energy branch of SONAR (OMMM-ENERGY model with a detailed representation of energy complexes) was developed by N.I. Suslov and A.A. Chernyshov, IEIE SB RAS in the middle of the 1980s [24-25]. Since that time several versions of this model for various time periods and regional and product structures have been specified and applied for analyzing issues of how the economy and the energy sector interact. The present version covers two periods - 2008-2020 and 2021-2030 - to calculate an assessment of investment project efficiencies and projections. The model identifies 6 regions (the European part of Russia, Urals, Tyumen oblast, Western Siberia, Eastern Siberia and Russian Far East) and 45 economic sectors, including 8 energy ones (production of crude oil with gas-condensate, natural and associated gas, coal and other types of solid fuel, heavy oil products, light oil products, coal processing products, electric power and heat). Moreover, several non-energy products, which are important for the energy sector, are identified too; they embrace drilling for oil and gas, pipeline transportation, production of special energy equipment, and petrochemistry.

The following features of energy sector were also considered in the model:

1. The specifics of capacities' reproduction in the oil and gas industry;

2. High dependence of resource industries in the fuel and energy complex on the availability and efficiency of exploration and development of fuel resource reserves in regions and the country in general;

3. Complexity of production of different types of energy (oil and associated gas, gas and gas condensate) by various technologies;

4. Specifics of a pipeline transportation of oil and gas.

5. Available alternatives for electricity and heat generation by various generalized technologies (combined heat and power plants, condensation power plants, nuclear energy stations, boiler and heating plants, and etc.) using different types of fuel (coal, fuel oil, and gas).

The classical version of OMMM assumes that sectoral production is based on old and new capacities. The old capacities are those which participated in production from the beginning to the end of the forecast period, while new ones give a production gain due to capital 
investments aimed at expansion and creation of capacities. The notion of "old capacities" in resource industries differs from that one used in manufacturing industries, since the resource industries deal with extraction of non-reproducible resources. Due to this fact, each new portion of capital investments means involvement of an additional share of industrial oil and gas reserves in production and could be considered as the cost of new capacities. Moreover, annual retirement of capacities in oil and gas production is rather high.

The above features motivated another approach to the description of a sectoral capacities reproduction process other than the one applied in the traditional OMMM. Its essence is to present parameters of capital investments per unit as nonlinear functions of the total capacity increase over the forecast period. Such functions, firstly, reflect price growth of new capacities due to transition from more effective oil and gas deposits to less effective ones, and, secondly, allow considering an increased retirement of production capacities.

The inclusion of specific conditions for presentation of oil and gas production is complemented with a block of oil and gas reserves which reflects links between an addition of production capacities and industrial reserves made by a given region or sector. This is done because such tracking of the reserves to production ratio should be included in forecasts. Reproduction laws observed in the sectors under study require this ratio to be within prescribed limits. If it is higher than the upper allowable level, then it would result in freezing of a considerable part of investments made in geological exploration. If the ratio is lower than the low allowable level, then there would be difficulties with formation of sound forecasts. So, given a reserves and production ratio, the reserves would serve as upper limits for variables of an addition of oil and gas capacities, while investments to reserves (oil and gas exploration) made in the above "drilling" sector are included in the total investment balance.

The description of "pipeline transportation" in this model differs from its description in OMMM by distinguishing between "old" and "new" flow efficiencies of interregional pipelines and including investments made to these interregional pipelines directly to the interregional oil and gas transportation. The investments made to pipelines of the interregional transportation per unit are constructed in the same way as a capital intensity of production. A high service life of pipelines predetermines a significant difference between coefficients of capital intensity of old and new pipeline sections.

\section{Examples of application of the OMMM-Energy: new energy technologies and displacement of domestic energy resources from foreign markets}

To illustrate the application of this model for assessing efficiency of various measures, we present the results of our study on how efficient the use of nontraditional renewables is. Our latest calculations based on the OMMM-Energy model were aimed at finding allowable limits of costs of added electricity generating capacities, which are included in the public electricity networks operating with renewables on assumption that their use is economically sound. We have determined that the cost for all regions included in the model would need to be 1700-1800 US dollars per $1 \mathrm{~kW}$. These estimations of a marginal capacities cost appear to be significantly lower than those indicated as expected average costs in the RF governmental program on Energy Efficiency and Development of the Russian Energy Sector at the level of 2500 dollars per $1 \mathrm{~kW}$. This could confirm the idea that use of renewables in Russia would require special governmental support measures.

We can present an example of our assessment on how a likely negative shift of Russian geopolitics involving higher competition in foreign markets of energy resources, would impact the Russian economy. Table 1 shows two series of our calculations on GDP growth 
(loss), the first - without adaptive import-substituting measures in relation to the investment goods producing sector and the second - with such measures. Parameters of changed export are given in Table 1, column 3. Let's consider some of the obtained results.

The first series of calculations (Table 1, section 1. No import-substituting measures) shows that the share of regions-exporters, due to which the total GDP losses would take place, on the one hand, are similar to each other, and, on the other hand, make up a considerable value - from $42 \%$ to $23 \%$. The European part of Russia among all regions would suffer the greatest GDP losses with increase from $57 \%$ to $73 \%$ by each parametric step. In our opinion, an interesting result is that no GDP losses would be suffered by the East Siberian economic region. Its GRP is $0.8-2.1 \%$ higher than that obtained for the central variant due to capital and material resources redistribution from nearby exporting regions. At the same time, the ranges of GRP losses are 4-6\% in West Siberia and 4-8\% in Tyumen oblast. The total GDP losses of the country evenly increases from $1.2 \%$ to $3.9 \%$ starting from the first iteration to the last one (see section 1.2, Table 1).

Table 1. GDP losses in macro-regions as function of drops in Tyumen oblast's export of pipeline gas and Kuzbas' export of coal to the western direction.

\begin{tabular}{|c|c|c|c|c|c|c|c|}
\hline $\begin{array}{c}\text { Export drop of } \\
\text { Gas - billion } \\
\text { m }^{3} \text {, Coa I- } \\
\text { million tons }\end{array}$ & $\begin{array}{c}\text { European } \\
\text { part of } \\
\text { Russia }\end{array}$ & $\begin{array}{c}\text { West } \\
\text { Siberia }\end{array}$ & $\begin{array}{c}\text { East } \\
\text { Siberia }\end{array}$ & $\begin{array}{c}\text { Russian } \\
\text { Far East } \\
\text { Region }\end{array}$ & $\begin{array}{c}\text { Tyumen } \\
\text { oblast }\end{array}$ & $\begin{array}{c}\text { Ural } \\
\text { Region }\end{array}$ & $\begin{array}{l}\text { Russian } \\
\text { Federation }\end{array}$ \\
\hline \multicolumn{8}{|c|}{ 1. No adaptive import-substituting measures } \\
\hline \multicolumn{8}{|c|}{ 1.1 Regional structure of the GDP losses, percent } \\
\hline 20 coal, 30 gas & 57.0 & 22.6 & -4.7 & 1.8 & 19.4 & 3.9 & 100 \\
\hline $40 \mathrm{coal}, 50$ gas & 59.6 & 17.0 & -4.3 & 2.5 & 20.4 & 4.8 & 100 \\
\hline $60 \mathrm{coal}, 70$ gas & 67.2 & 13.5 & -3.1 & 3.2 & 12.0 & 7.3 & 100 \\
\hline 80 coal, 90 gas & 72.6 & 9.5 & -3.7 & 2.2 & 13.0 & 6.3 & 100 \\
\hline \multicolumn{8}{|c|}{ 1.2 GDP losses against those in the central variant, percent } \\
\hline 20 coal, 30 gas & -1.0 & -4.3 & 0.8 & -0.5 & -3.6 & -0.8 & -1.2 \\
\hline 40 coal, 50 gas & -1.8 & -5.6 & 1.3 & -1.2 & -6.6 & -1.6 & -2.1 \\
\hline 60 coal, 70 gas & -2.9 & -6.4 & 1.4 & -2.2 & -5.6 & -3.5 & -3.0 \\
\hline 80 coal, 90 gas & -4.0 & -5.9 & 2.1 & -2.0 & -7.8 & -3.9 & -3.9 \\
\hline \multicolumn{8}{|c|}{ 2. With adaptive import-substituting measures } \\
\hline \multicolumn{8}{|c|}{ 2.1. Regional structure of the GDP losses, percent } \\
\hline 20 coal, 30 gas & 194.5 & -60.9 & 7.0 & 2.4 & -34.5 & -8.6 & 100 \\
\hline 40 coal, 50 gas & 23.4 & 40.2 & -6.9 & 2.5 & 40.7 & 0.0 & 100 \\
\hline $60 \mathrm{coal}, 70$ gas & 55.9 & 21.6 & -5.1 & 2.9 & 23.4 & 1.3 & 100 \\
\hline 80 coal, 90 gas & 67.1 & 15.8 & -3.0 & 4.0 & 12.5 & 3.6 & 100 \\
\hline \multicolumn{8}{|c|}{ 2.2 GDP losses against those in the central variant, percent } \\
\hline 20 coal, 30 gas & 0.4 & -1.5 & 0.2 & 0.1 & -0.8 & -0.2 & 0.2 \\
\hline 40 coal, 50 gas & -0.2 & -4.5 & 0.7 & -0.4 & -4.4 & 0.0 & -0.7 \\
\hline 60 coal, 70 gas & -1.3 & -5.5 & 1.2 & -1.1 & -5.8 & -0.3 & -1.6 \\
\hline 80 coal, 90 gas & -2.4 & -6.3 & 1.1 & -2.4 & -4.9 & -1.5 & -2.5 \\
\hline
\end{tabular}

Source: Calculations based on the OMMM-ENERGY

The second series of calculations (see Table 1, section 2,) assumes that adaptive measures for development of domestic production in the country would allow the replacement of the short deliveries of imported investment engineering products due to a drop in exported energy carriers (all other things being equal). As the first series, the second 
one shows the highest relative losses in regions-exporters - a $1.5-6 \%$ GRP drop in West Siberia and $0.8-6 \%$ - in Tyumen oblast.

At the same time, a relatively small market fluctuation of export observed in the first iteration would not result in the total GDP loss of the country; only the regions-exporters and Ural suffer losses. The compensating machine-building production would develop in 4 regions in the following territorial proportions: the European part of Russia (79.5\%), West Siberia (6.5\%), Ural (13.6), and Tyumen oblast (0.4\%). Though such regional structure of growth in machine-building production (with a prevailing role of the European part of Russia) remains the same in all iterations, the second iteration shows the GDP loss (see Table 1, section 2.2,). If the country developed import-substituting productions, the loss observed in the iterations beginning from the second one would be 1.4 percentage points lower than those in case of no adaptive measures applied.

\section{References}

1. G. Granberg, Optimization of spatial proportions of national economy. Moscow: Ekonomika. (1973) (in Russian)

2. N.F. Shatilov, Modeling the expanded reproduction. Moscow: Ekonomika. (1967) (in Russian)

3. V.M. Gilmundinov, Developing the model of intersectoral balance, Bulletin of NSU: socio-economic sciences, 4, pp. 5-16 (2010) (in Russian)

4. V.K. Ozerov, V. N. Pavlov, A.O. Baranov, Dynamic multisectoral model taking into account duration of the fixed assets reproduction period, Economics and mathematical methods, 1, pp. 87-94 (1987) (in Russian)

5. Study of Russian economy applying the models with fuzzy parameters. NSU, IEIE SB RAS, Novosibirsk. (2009) (in Russian)

6. A.G. Granberg, V. I. Suslov, S. A. Suspitsyn, Multiregional systems: economicmathematical research ("Council for epy study of the production forces", Siberian scientific publishing, Novosibirsk. (2007) (in Russian)

7. A.G. Granberg., V. E. Seliverstov, V. I. Suslov, A. G. Rubinshtein, The SYRENA (Synthesis of Regional and National Models) model complex, Advances in InputOutput Analisis, Technology, Planning, and Development, Oxford, New York, pp. 161$173(1991)$

8. A.G. Granberg, V. I. Suslov, S. A. Suspitsyn, Economic-mathematical studies of multiregional systems, Region: economics and sociology, 2, pp. 120-150 (2008) (in Russian)

9. System modeling and analysis of mezo- and microeconomic objects. SB RAS, Novosibirsk. (2014) (in Russian)

10. Methodology and practice of creating and using regional energy balances. IEIE SB RAS, Novosibirsk. (2010) (in Russian)

11. N.I. Plyaskina, Problems of subsoil use and methodology to create investment programs for oil and gas resources development, Drilling and oil, 11, pp. 60-83 (2007). (In Russian)

12. W. Izard, Interregional and regional input-output analysis: a model of space economy, The Review of Economics and Statistics, 33, pp. 318-328 (1951)

13. H. Chenery, Regional analysis, in H. B. Chenery, P. G. Clark, \& V. Cao Pinna (Eds.), The structure and growth of the Italian economy. (United States Mutual Security Agency, Rome, pp. 96-115 1951)

14. L.M. Moses. The stability of interregional trading patterns and input-output analysis, American Economic Review, 45, pp. 803-832 (1955) 
15. W. Leontief, A. Strout, Multiregional Input-Output Analysis, in T. Barna (ed.), Structural Interdependence and Economic Development (Macmillan (St. Martin's Press), London, pp. 119-149 1963)

16. W. Leontief, H. B. Chenery, P. G. Clark, J. S. Duesenberry, A. R. Ferguson, A. P. Grosse, R. H. Grosse, M. Holzman, W. Isard, H. Kistin, Studies in the Structure of the American Economy. (White Plains, International Arts and Science Press, New York, 1953)

17. P.G. McGregor, J. K. Swales, K.R. Turner, The CO2 'trade balance' between Scotland and the rest of the UK: Performing a multi-region environmental input-output analysis with limited data, Ecological Economics 66, pp. 662-672 (2008)

18. K.R. Turner, M. Lenzen, T. Wiedmann, J. Barrett, Examining the global environmental impact of regional consumption activities-Part 1: A technical note on combining inputoutput and ecological footprint analysis. Ecological Economics 62, pp. 37-44 (2007)

19. T. Wiedmann, M. Lenzen, J. Barrett, K. Turner, Examining the Global Environmental Impact of Regional Consumption Activities - Part 2: Review of input-output models for the assessment of environmental impacts embodied in trade, Ecological Economics, 61(1), pp. 15-26 (2007)

20. S.J. Ha, G. Hewings, K. Turner, An interregional input-output analysis of the pollution content of trade flows and environmental trade balances between five states in the US Mid-West (STRATHCLYDE Discussion Papers in Economics, NO. 09-20 (2010)

21. M. Horridge, W. Glyn, The economic impact of a construction project, using, SINO TERM, a multi-region CGE model (Center of Policy Studies, Monash University, General Working Paper, No. G-164 (2007)

22. M. Horridge, J. Madden, G. Wittwer, 2005, Using a highly disaggregated multiregional single country model to analyze the impacts of 2002-03 droughts on Australia, Journal of Policy Modeling, 27, pp. 258-308 (2005)

23. The Future of the World Economy. A United Nations Study by Wassily Leontief et al. (Oxford University Press, New York, 1977).

24. N.I. Suslov, A. A. Crernyshov, Modeling interactions of multisectoral complexes within national economy system: Spatial national economy models of interrelations of multisectoral complexes. Novosibirsk:Nauka (1992) (in Russian)

25. N.I. Suslov, A. A. Crernyshov, Optimization multiregional multisectoral models: Application of OMMM for analysis of multisectoral complexes Novosibirsk:Nauka. (1989) (in Russian) 